\title{
METODOLOGIAS DE ESTUDOS DA NARRATIVA E DO DISCURSO NA INTERPRETAÇÃO DE FONTES ORAIS DE HISTÓRIA
}

\section{METHODOLOGIES OF NARRATIVE AND DISCOURSE STUDIES IN THE INTERPRETATION OF ORAL SOURCES OF HISTORY}

\author{
Glauco Vaz Feijó ${ }^{1}$
}

\begin{abstract}
Resumo: A partir das considerações de uma historiadora e de um historiador sobre a ausência do uso de metodologias de estudos da linguagem no manejo de fontes orais de história, proponho uma memtodologia híbrida de interpretação de narrativas orias que se remete ao trabalho seminal de William Labov e se desdobra no uso da Análise Crítica de Narrativa e da Análsie Crítica de Discurso como metodologias interdisciplinares com potencial para contribuir com o trabalho de historiadores que utilizam fontes orais com feramentas metodológicas que possibilitam o trabalho sitemático com a linguagem.
\end{abstract}

Palavras-chave: Narrativas Orais; Análise Crítica de Narrativa; Análise Crítica de Discurso.

Abstract: Based on the considerations of two historians about the absence of the use of methodologies of language studies in the management of oral sources of history, I propose a hybrid interpretation of oral narratives that refers to the seminal work of William Labov and deploys the use of Critical Narrative Analysis and Critical Discourse Analysis as interdisciplinary methodologies with the potential to contribute to the work of historians who use oral sources with methodological tools that enable the systemic work with language.

Keywords: Oral Narratives; Critical Narrative Analysis; Critical Discourse Analysis.

\section{Introdução}

Há mais de uma década a historiadora Verena Alberti chamava a atenção para o déficit na pesquisa com fontes orais de instrumentos interpretativos apropriados ao trabalho com a linguagem: Um acontecimento, uma situação vivida pelo entrevistado, não pode ser
transmitido a outrem sem que seja narrado. Isso significa que ele se constitui
(no sentido de tornar-se algo) no momento mesmo da entrevista. Ao contar
suas experiências, o entrevistado transforma aquilo que foi vivenciado em
linguagem, selecionando e organizando os acontecimentos de acordo com
determinado sentido. Esse trabalho da linguagem em cristalizar imagens que
remetem a, e que significam novamente, a experiência é comum a todas as
narrativas (...). Mas talvez não tenhamos dado ainda a devida atenção para
esse trabalho da linguagem nas chamadas "fontes orais" (ALBERTI, 2003, p.
1).

Na mesma linha, quase uma década depois, Lynn Abrams reclamava que:

\footnotetext{
${ }^{1}$ Doutor em História pela Universidade de Brasília (UnB) em regime de cotutela doutoral com a FriedrichSchiller-Universität Jena (FSU Jena), onde recebeu o título de doctor philosophiae. Professor do Instituto Federal de Brasília (IFB), Brasília, DF, Brasil. E-mail: glauco.feijo@ifb.edu.br
} 
Oral history sources are also narrative sources, so historians must use theories devised from the interpretation of literacy and folklore texts, and those derived from linguistics and psychology in order to gain insight into the meaning as opposed to the content of the interview (ABRAMS, 2010, p. 18).

Insprirado por reflexões como essas, cada vez mais comuns em tempos de interdisciplinaridade teórica, mas ainda não tão frequentes na práxis acadêmica frente às resistências dos regimes diciplinares, traço neste artigo uma proposta de interpretação de narrativas orais, que se sustenta em uma hibridização de métodos interpretativos vindos dos estudos sobre a linguagem. Tento aprofundar aqui um pouco mais da proposta metodológica que desenvolvi no meu trabalho de doutorado (FEIJÓ, 2015) e que apresentei posteriormente no Congresso Iberoamericano de Investigação Qualitativa (FEIJÓ, 2017).

No presente artigo, parto de uma breve contextualização do trabalho seminal do linguista William Labov sobre a interpretação de narrativas orais, que é em parte absorvido na proposta metodológica desenvolvida, e sigo por uma discussão sobre a virada epistemológica nos estudos de narratologia que ganharam consitência a partir da década de 1990 por meio de uma crítica à narratologia clássico-estruturalista e de uma ampliação da ideia de narrativa para os campos dos estudos de cultura, conforme a instigante proposta de Mike Bal (1999) de promover uma narratological analysis of culture e a cultural analysis of narrative. Por fim, complemento a interpretação do trabalho da linguagem em narrativas orais com uma aproximação também com os estudos de discurso.

Incluída no narrative turn, a proposta de uma Análise Crítica de Narrativa (ACN), conforme apresentada por Motta (2013), é também retomada para ser incluída no método de interpretação de narrativas orais proposto, que, além das contribuições de Labov, Motta e outros autores do narrative turn, incorpora ainda contibuições da Análise Crítica de Discurso (ACD) por meio de ideias de Teun van Dijk e Theo van Leuween e de algumas categorias metodológicas de Norman Fairclough.

\section{Labov e as narrativas orais. Narrative turn e a análise crítica de narrativa}

O envolvimento de Labov com a narratologia foi construído de forma intercalada com seu papel de ponta na sociolinguística. Em 1967, Labov lançou bases para a interpretação de narrativas orais ao publicar com Waletzky (LABOV; WALETZKY, 2003) artigo em que as narrativas orais eram seminalmente introduzidas no campo de 
estudos de narrativas. Daí em diante, Labov dedicou-se quase que exclusivamente à sociolinguística e, como sabemos, a narratologia estruturalista predominou no campo de estudos de narrativa, com pouca ênfase sobre as narrativas orais. O trabalho seminal de Labov e Waletzky não foi, contudo, esquecido. Prova disso foi a comemoração em 1997 dos trinta anos de publicação do artigo escrito com Waletzky, por meio da publicação de um número especial revista Narrative Inquiry, à época intitulada The Journal of Narrative and Life History. O número especial, intitulado Oral versions of personal experience. Three decades of narrative analysis, foi coordenado por Bamberg (1997) e reuniu mais de meia centena de autores, como Jerome Bruner e Gerald Prince.

Desde 1997, Labov voltou suas atenções para a interpretação de narrativas orais e publicou regularmente artigos que aprofundam categorias interpretativas presentes ou anunciadas em 1967. Assim o faz, por exemplo, com as categorias orientação, complicação, avaliação e resolução, já presentes no trabalho com Waletzky e retomadas em vários outros textos após 1997.

O método de interpretação de narrativas orais aqui proposto baseia-se nas categorias desenvolvidas por Labov, mas orienta-se sobretudo pela crítica culturalista feita pela nova narratologia aos estudos narratológicos clássicos predominantes dos anos 1960 aos anos 1980. Tal crítica pode ser direcionada também a Labov, o que de forma alguma invalida o trabalho desenvolvido pelo autor, nem mesmo tem a crítica à narratologia clássica o intuito de negar as contribuições dos grandes narratologistas, tratase de uma superação, é verdade, mas não de uma negação de categorias que ainda se mostram fundantes para a interpretação de narrativas, como pode nos assegurar Mieke Bal, que constrói uma das mais instigantes críticas à narratologia estruturalistas, depois de ter sido uma das suas autoras mais importantes. Também Motta, outro autor fundamental para o método de interpretação de narrativas orias aqui proposto, trabalha fundamentalmente com conceitos da narratologia clássica readaptados para a interpretação cultural crítica. Nesse ponto o mais importante talvez seja frisar que, se as categorias de Labov são úteis como técnicas para o manejo das fontes orais a serem interpretadas, elas não fundamentam a interpretação em si, na interpretação são fundantes as ideias presentes na virada narrativa. Uso, assim, uma estruturação baseada em Labov como ponto de partida possível para a interpretação necessária, mas de forma alguma como uma possível interpretação. A interpretação buscada é cultural e não estrutural. A narratologia, a qual me filio, é mais cultural que linguística, pois "a ênfase da análise aqui 
proposta recai sobre o processo de comunicação narrativa, mais do que sobre a narrativa como obra fechada" (MOTTA, 2013, p. 11).

Depois do chamado narrative turn dos anos 1990, a narratologia, incluído o estudo das "narrativas orais", tornou-se um dos campos mais propícios para o diálogo entre diferentes áreas que tentam romper fronteiras disciplinares. Para Vera e Ansgar Nünning, a abrangência dos estudos de narrativa hoje é uma de suas características mais notáveis.

\begin{abstract}
Muitas das novas abordagens trazem de volta para o antes claramente definido campo da narratologia exatamente as categorias que o paradigma de uma cientificidade precisa anteriormente e conscientemente apagou em nome da exatidão: as dimensões da história, da variabilidade histórica das formas narrativas, da estética, da ética, da ideologia, das interpretações e, finalmente, a dimensão sociocultural, que abrange categorias como raça, classe, gênero (NÜNNING; NÜNNING, 2002, p. 20, tradução nossa). ${ }^{2}$
\end{abstract}

Para Motta (2013), a perspectiva da nova narratologia enfatiza sobretudo a determinação cultural das narrativas, sendo-lhe, portanto, a produção cultural de sentidos um fator prévio. Essa nova narratologia "procura entender como os sujeitos sociais constroem intersubjetivamente seus significados pela apreensão, representação e expressão narrativa da realidade" (MOTTA, 2013, p. 79). Na trilha dessa interpretação, Motta propõe passos a seguir nessa interpretação de narrativas focada na produção cultural de sentidos. A proposta de Motta compõe também a base da proposta de interpretação de narrativas orais construídas na próxima seção desse artigo.

Na proposta apresentada parto da sugestão de abordar as narrativas interpretadas concomitantemente por três planos distintos: "plano da estória", "plano da expressão" e "plano da metanarrativa" (MOTTA, 2013). Tomo, contudo, a liberdade de alterar os nomes, trabalhando com "plano da história" e "plano do texto", e mantendo a denominação "plano da metanarrativa".

Com a primeira alteração, ao mesmo tempo que evito entrar na discussão sobre as diferenças ou similitudes entre narrativas ficcionais e narrativas fáticas, não deixo de marcar posição sobre a crença na existência e a importância de diferenças entre elas. Com a segunda alteração, ao usar "plano do texto" em vez de "plano da expressão", quero dar ênfase às estratégias discursivas que são os aspectos mais relevantes e reveladores deste plano, também para Motta, que descreve o plano da expressão como sendo "o plano da

\footnotetext{
${ }^{2}$ Viele der neuen Ansätze reimportieren in das einstmal so klar definierte Feld der Narratologie genau jene Kategorien, die dieses um Exaktheit so bemühte Paradigma präziser Wissenschaftlichkeit zuvor bewußt ausgeblendet hatte: die Dimensionen der Geschichte und der historischen Variabilität von Erzählformen, der Ästhetik, der Ethik, der Ideologie, der Interpretation und schließlich die soziokulturelle Dimension, die solche Kategorien wie race, class und gender umfaßt (NÜNNING; NÜNNING, 2002. p. 20).
} 
linguagem, o plano da superfície do texto (...). Plano do discurso propriamente dito" (MOTTA, 2013, p. 136).

No "plano da história", reconstruo as narrativas interpretadas para descobrir seus enredos, identificando seu início, meio e fim (LABOV, 2010b), e, portanto, "sua inteligibilidade como totalidade" (MOTTA, 2013, p. 140). O enredo se constrói por sequências-tipo, episódios, estratégias argumentativas, atores e seus conflitos, que, ao serem desvendados e interpretados, ajudam-nos a entender o contexto histórico-cultural que permite a construção da narrativa; nos ajudam a vislumbrar o contexto metanarrativo, que é o que nos interessa em uma interpretação pós-estruturalista de narrativas.

Por meio a observação das estratégias argumentativas e dos atores da narrativa, a atenção se centra no "plano do texto", em que os usos da linguagem são reveladores da história, da cultura e das relações sociais que embasam as narrativas interpretadas. Em vez de seguir única e fielmente com as ferramentas da ACN inicialmente utilizadas, ao escolher trabalhar com atores em vez de personagens, integro transdisciplinarmente a ACD à interpretação proposta, lançando mão da interpretação da representação de atores sociais proposta por Theo van Leeuwen (2008), que servem de ponte para unir os estudos de narrativa com os estudos de linguagem, aos que chegamos ao incorporar categorias metodológicas da Análise Crítica de Discurso de Norman Fairclough.

Envolvendo e cortando os planos da história de do texto, em todos os tempos e sentidos, está o "plano da metanarrativa", plano da "estrutura profunda que evoca os imaginários culturais" (MOTTA, 2013, p. 139). Esse plano permeia toda a interpretação e nos remete a questões histórico-culturais anteriores à narrativa interpretada, nos remete a categorias ideológicas sobre as quais as narrativas se constroem, sendo os enredos narrativos e as estratégias de linguagem entendidos como manifestações de superfície de conflitos profundos enraizados na cultura e latentes no discurso.

\section{Análise crítica de narrativas orais}

Para a interpretação de narrativas orais, orientado pela divisão da interpretação em dois momentos, o "plano da história" e o "plano do texto", cortados pelo "plano da metanarrativa", proponho iniciar a interpretação pelo "plano da história", ou seja, pela interpretação da narrativa em si, seguindo movimentos de interpretação propostos por Motta (2013). Cabe ressaltar não se deve entender que tais movimentos de interpretação sejam sequenciais, pois eles se entrecruzam e são antes simultâneos. Proponho que sejam 
seguidos os cinco primeiros dos sete movimentos descritos por Motta (2013), pois considero estarem aí incluídos os outros movimentos.

Motta denomina seu primeiro movimento interpretativo da narrativa como “compreender a intriga como síntese do heterogêneo" (MOTTA, 2013, p. 140). Esta é na verdade a fase de reestruturação e de preparação do texto narrativo para a interpretação; é o movimento mais importante, pois o seu resultado será o objeto da interpretação da narrativa colhida. Nesse primeiro movimento, é preciso "empapar-se da história" (MOTTA, 2013, p. 140) para identificar seus episódios e encadeamentos básicos. O principal passo nesse movimento é identificar o início, o meio e o fim da história, reconstruindo retrospectivamente a sua totalidade. Segundo Motta, no movimento inicial:

$\mathrm{O}$ analista precisa decompor e recompor a história com rigor e identificar suas partes componentes, as sequências básicas, os pontos de virada ou inflexões essenciais, os limites dos episódios parciais, as conexões entre eles, os conflitos principais e secundários, o protagonista e o antagonista (MOTTA, 2013, p. 141).

Esse processo de decomposição e recomposição da história precisa ser aqui descrito, uma vez que a interpretação empreendida parte de seu resultado, da "narrativa recomposta em uma reconfiguração sintética do que antes parecia desconectado" (MOTTA, 2013, p. 143), emprestando continuidade, coesão e coerência à narrativa oral, que, muitas vezes, não possui essas características da forma como é narrada. Para Motta, esse novo enredo, "embora metodologicamente resumido em uma sinopse, é mais complexo porque confere ao objeto outras significações” (MOTTA, 2013, p. 143).

É nesse movimento de "compreensão da intriga como síntese do heterogêneo", para decompor e recompor a narrativa, que me são fundamentais as ferramentas metodológicas de William Labov (1997, 2003, 2006, 2010a, 2010b) descritas em alguns de seus trabalhos sobre análise de narrativas orais iniciados em 1967 em parceria com Waletzky (LABOV; WALETZKY, 2003). As categorias labovianas mais importantes que utilizo para a reelaboração das narrativas são o evento mais reportável, o evento inicial e a matriz inicial (LABOV, 2010b). Trabalho também com a ideia de préconstrução narrativa como necessária à reconstrução narrativa (LABOV, 2006) e, posteriormente, $\mathrm{com}$ as categorias orientação-complicação-avaliação-resolução desenvolvidas por Labov e Waletzky (2003). Devo aqui valer-me de Labov para explicar então cada uma dessas categorias.

Labov define o evento mais reportável (e) como "the event that is the least common and has the greatest consequences for the life chances of the actors involved" 
(LABOV, 2010b, p. 7). A identificação deste evento mais extraordinário ou mais inesperado de uma narrativa é o primeiro passo para a sua reconstrução, pois é a partir dele que se chegará ao evento inicial que responde a pergunta "Por onde começar?". O caminho para o evento inicial (ei) segue uma cadeia retrospectiva de causalidade que parte do evento mais reportável (e0) e chega ao evento inicial (ei) passando pelos eventos, e-1, e-2, e-3, ... e-n, aos quais se chega por meio de uma relação de causalidade evidenciada pela introdução da conjunção causal "porque" (because) entre os eventos da cadeia. Quanto mais extraordinário o evento, maior será o seu grau de reportabilidade e menor o seu grau de credibilidade, o que Labov chama de "paradoxo da reportabilidade" (LABOV, 2010b). Quanto menor a credibilidade de um evento maior a necessidade de introdução de eventos na cadeia retrospectiva com explicações (causas) que tornem o evento crível. Contudo, quanto maior o esforço para aumentar a credibilidade de um evento, menor se torna a sua reportabilidade, menor o seu caráter surpreendente quando ele surge na narrativa. Em uma narrativa conversacional de trajetória de vida, relativamente curta se comparada, por exemplo, com uma narrativa de história de vida pormenorizada, pode ser bastante significativo o caráter de surpresa do evento mais reportável. De qualquer forma, identificar esse elemento, independentemente do grau de sua reportabilidade é o primeiro passo para responder a pergunta “Por onde começar?" e para conseguir a reconstrução resumida da narrativa, que será o objeto da interpretação com as ferramentas da ACN, uma vez que no uso das ferramentas da ACD de van Leeuwen são tomadas como unidades de interpretação recortes do texto tomado na íntegra.

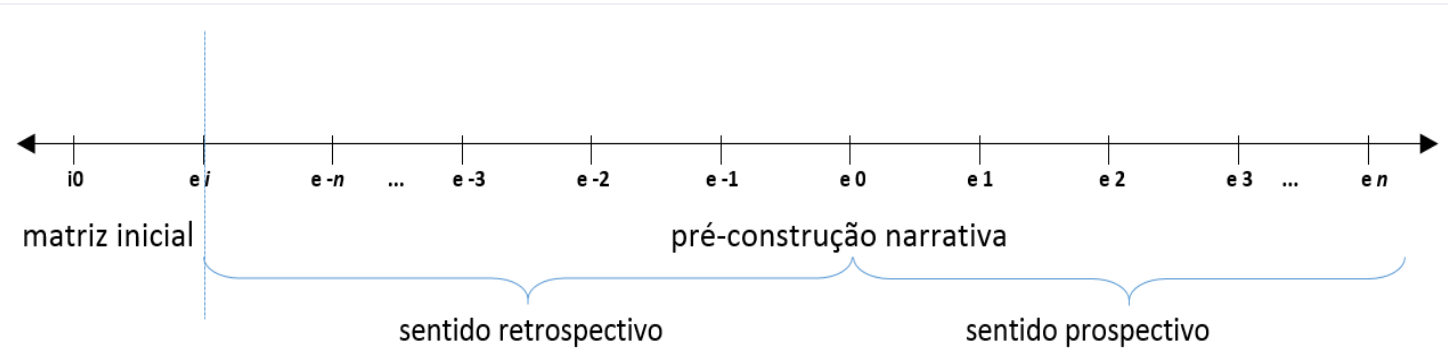

Figura 1: Representação gráfica da construção pré-narrativa.

Fonte: Labov, 2010b.

Seguindo-se a cadeia retrospectiva de causalidade, chega-se ao evento inicial (ei), que Labov define como "an event e-n with no immediate or obvious cause. This may be termed the initiating event, because it initiates the chain that leads to the most reportable event" (LABOV, 2010b, p. 8). Ainda com Labov: 
An answer to the question, "How did (e-n) happen?" would be "I don't know. We were only..." followed by a description of ordinary behavior. We will call this behavior the initial matrix i0, for which the question "Why did you do that?" would be heard as foolish or inappropriate (LABOV, 2010b, p. 8).

Os comportamentos ordinários que antecedem o evento inicial são chamados por Labov de matriz inicial (i0). Chegar a esses comportamentos ordinários que servem de resposta à pergunta sobre as causas do evento inicial (ei) e, portanto, como marca de termos chegado ao evento inicial (ei), cumpre o objetivo primeiro do modelo de Motta (2013) de definir o início, o meio e o fim da história. Identifica-se e parte-se de "e0" para chegar a "ei" e a "i0". Identificando essa "mancha narrativa", esses marcos do "perímetro" que cerca a área coberta pela narrativa, é possível partir para a préconstrução narrativa, um artifício de interpretação que vai permitir a reconstrução da narrativa no passo seguinte. A pré-construção é a própria cadeia de eventos iniciada a partir do evento mais reportável (e0), movendo-se no sentido retrospectivo até a matriz inicial (i0) e, no sentido prospectivo até o final da narrativa, que pode ser um desenlace ou não, como costuma ser o caso das narrativas de composição aberta aqui interpretadas. Nas palavras de Labov:

Pre-construction begins with this most reportable event and proceeds backwards in time to locate events that are relinked causally each to the following one, a recursive process that ends with the location of the unreportable event--one that is not reportable in itself and needs no explanation (LABOV, 2006, p. 16)

Desde 1997, Labov voltou suas atenções para a interpretação de narrativas orais e vem publicando regularmente artigos que, em maior ou menor grau, dialogam com e aprofundam categorias interpretativas já presentes ou anunciadas em 1967. Assim o faz com as categorias orientação, complicação, avaliação e resolução, já presentes no trabalho com Waletzky e retomadas em vários outros textos após 1997. Creio ser bastante para a utilização que faço do trabalho de Labov (fundamental para a estruturação da interpretação, mas não para a interpretação em si) recorrer a citações de seus trabalhos na definição das últimas categorias utilizadas para a "estruturação geral da narrativa" (LAVOB, 2003, p. 94); quais sejam, orientação, complicação, avaliação e resolução.

Nos termos de Labov, "a narrative normally begins with an orientation, introducing and identifying the participants in the action: the time, the place, and the initial behavior" (LABOV, 2010a, p. 547). A orientação está então normalmente ligada à matriz inicial, encontra-se quase sempre antes do evento inicial, antes da primeira sentença narrativa e é constituída por sentenças independentes. Blocos de orientação podem, contudo, aparecer também em outros momentos da narrativa já iniciada. 
Como complicação, Labov define que "a clause of complicating action is a sequential clause that reports a next event in response to a potential question, And what happened [then]?” (LABOV, 1997, p. 402). A avaliação de um evento da narrativa surge quando há uma "information on the consequences of the event for human needs and desires" (LABOV, 1997, p. 403). Por fim, sobre a resolução, Labov propõe que "the resolution of a personal narrative is the set of complicating actions that follow the most reportable event" (LABOV, 1997, p. 412).

Após um número relativamente grande de citações de Labov, sinto-me obrigado a reforçar o método interpretativo aqui desenvolvido. Labov é fundamental para a reconstrução das narrativas a serem interpretadas, mas não tem nenhum peso na interpretação que se faz dessas reconstruções. O uso que faço de suas ferramentas é metodológico, mas não necessariamente interpretativo, a não ser pelo fato de ser fundamental na construção do texto a ser interpretado seguindo-se propostas de Motta (2013) e da nova narratologia. As categorias de Labov são indicadas apenas para marcar as reconstruções narrativas, pois o trabalho interpretativo em nada se aproxima da proposta quase matemática iniciada por Labov e Waletzky em 1967.

Anterior e complementarmente ao trabalho com as ferramentas elaboradas por Labov, a reelaboração das narrativas aqui interpretadas parte do "empapar-se da história" (MOTTA, 2013). Após a leitura e audição repetida das entrevistas, os episódios das narrativas foram identificados e tomados como unidades de interpretação, conforme proposição de van Dijk (1982). Adapto a sugestão de van Dijk de adotar os episódios como unidade de interpretação do discurso, tomando-os como unidades de interpretação narrativa a partir da definição de episódio de Reis e Lopes:

Unidade narrativa não necessariamente demarcada exteriormente, de extensão
variável, na qual se narra uma acção autônoma em relação à totalidade da
sintagmática narrativa, acção essa que se conexiona com o todo em que se
insere por meio de qualquer factor de redundância (a personagem que
protagoniza os diferentes episódios de uma narrativa, o espaço em que eles se
desenrolam, as dominantes temáticas que regem a narrativa etc.) (REIS;
LOPES, 2007, p. 127).

Embora a definição de episódio de Reis e Lopes (2007) se aproxime da definição de episódio de van Dijk, que o define como uma "unidade semantica" e embora a assunção dos episódios como unidades de interpretação decorra diretamente da leitura de van Dijk, na interpretação que proponho dos episódios identificados pela definição de Reis \& Lopes não sigo exatamente o mesmo caminho de van Dijk. Em vez de trabalhar os episódios a partir da perspectiva de uma análise discursiva, abordando-os desde suas 
proposições, sentenças ou macroposições; proponho a reconstrução de cada episódio desde a perspectiva de uma interpretação de narrativa, abordando-os a partir de sua ordenação sequencial e da identificação dos marcos e procedimentos de reconstrução narrativa propostos por Labov e Waletzky (2003) e de sua inserção em sequências narrativas básicas, compostas por "situação inicial, perturbação e solução".

Mesmo que prefira a definição de episódio de Reis e Lopes (2007), tomo emprestado de van Dijk não apenas a ideia de trabalhar os episódios como unidades mínimas de análise, mas observo também suas orientações para identificação linguística das mudanças de episódio, sejam elas semânticas ou gramaticais. Van Dijk enumera algumas marcas textuais que ajudam a identificar as quebras de episódios; resumidamente são elas: a) pausas e hesitações nos textos orais; b) indicadores de mudança tempo; c) indicadores de mudança de lugar; d) indicadores de mudança de "elenco"; e) palavras de introdução ou mudança de predicação; f) introdução de novos predicados que não se enquadram no predicado anterior; g) mudança de perspectiva da narração (VAN DIJK, 1982, p. 181).

Por fim, os encaixes e encadeamentos dos episódios são identificados como forma de se descobrir inicialmente a complexidade da narrativa, o que ajuda na compreensão das estratégias utilizadas em sua estruturação. Na distinção de encaixe e encadeamento, trabalho também com as definições de Reis e Lopes, para quem nos encadeamentos "as sequências se concatenam linearmente, sendo o final de cada uma o ponto de partida da seguinte" (REIS; LOPES, 2007, p. 121), enquanto que nos encaixes "uma ou mais sequências surgem engastadas no interior de outra que as engloba" (REIS; LOPES, 2007, p. 121). Os encaixes podem, entre outras coisas, servir de explicação causal, explicitando as ações que guiaram o comportamento do narrador (REIS; LOPES, 2007).

Os encadeamentos ou encaixes são apenas uma das estratégias de construção do narrador, as quais destaco também no primeiro movimento para serem interpretadas depois. Se tratamos, por exemplo, de uma narrativa autobiográfica, os limites entre narrador e autor são extremamente tênues e chega a ser duvidosa a pertinência em procurá-los. Contudo, mesmo nesse caso, autoras e narradoras não são exatamente as mesmas, pois se considerarmos que as identidades narradas são (re)construídas no momento da narração, podemos considerar que durante a narração a (re)construção identitária é feita por meio da construção do narrador. A diferença sútil reforça então o processo fluido de identificação que se quer ressaltar. Em termos da narratologia clássica, temos nas narrativas interpretadas narradoras autodiegéticas, protagonistas de suas 
histórias, que são narradas em primeira pessoa, em que o tempo da narração oscila entre a simultaneidade e a posteridade aos eventos narrados, e o foco da narrativa é predominantemente interno, podendo apresentar às vezes características de omnisciência. Contudo, mais do que descrever o tipo de narrador/a, importa verificar como eles/elas são construídos/as, o que tento fazer durante a interpretação.

Com todas essas categorias metodológicas nas mãos, a desmontagem e remontagem da narrativa é feita de acordo com os seguintes passos: audição e leituras repetidas da narrativa; identificação dos episódios da narrativa; assunção dos episódios como unidade de; desconstrução, reconstrução e concatenação dos episódios a partir das categorias e procedimentos de Labov e das categorias propostas por Motta, como marcos da narrativa a serem identificados neste primeiro movimento pré-interpretativo (iníciomeio-fim, episódios e sequências básicas). Feito isso, temos a reelaboração resumida da narrativa e é possível partir para os próximos movimentos de interpretação, que, a rigor, já são acionados, todos eles, no primeiro movimento de "compreensão da intriga como síntese do heterogêneo".

O segundo e o terceiro movimentos propostos por Motta consistem em "compreender a lógica do paradigma narrativo" e "deixar surgir novos episódios" (MOTTA, 2013, p. 147). Nesses momentos são descortinadas as relações causais entre as partes da narrativa, tanto entre as sequências menores de cada episódio (segundo movimento), como entre os episódios (terceiro movimento). Aqui é descoberto o "tempo da narrativa", que, segundo Motta, "é mais lógico que cronológico", sendo que "a lógica da narrativa está na conexão de uma ação ou sequência por causa da outra e não uma depois da outra" (MOTTA, 2013, p. 148).

Sempre atrás de desvendar a lógica da narrativa por meio das estratégias e movimentos utilizados na narração, cada episódio pode ser dividido em movimentos menores, que são ordenados dentro de cada episódio e interpretados, sempre que sua sequenciação na ordem cronológica ou causal revelar uma possível estratégia narrativa. Esses movimentos internos a cada episódio não devem ser confundidos com os cinco movimentos de Motta utilizados para construir a interpretação. Mesmo que sejam acionados pelo intérprete, os movimentos internos aos episódios são movimentos da própria narração e não da interpretação.

Reconstruída a narrativa em uma síntese coerente, a interpretação recai em grande parte sobre as estratégias narrativas empregadas na organização do "projeto dramático", que é assim definido por Motta: 
Em resumo, ele começa com uma situação estável interrompida por uma perturbação que leva à transformação da situação. Ações da personagem principal enfrentam as forças da perturbação a fim de solucionar o problema e recuperar a estabilidade. Outras personagens podem ajudar a solucionar ou a complicar o problema e antagonizar a personagem principal. Isso gera jogos de ações cada vez mais intensas até que a perturbação é solucionada (MOTTA, 2013, p. 126).

A interpretação dos episódios e a elucidação do "projeto dramático" passam obrigatoriamente pelos personagens, espaços, conflitos e tensões narrados e, fundamentalmente, ainda que de forma breve, pela construção do narrador, já mencionada. A construção das personagens é observada fundamentalmente no quinto movimento, no qual opto por trabalhar com a proposta de van Leeuwen de "representação de atores sociais", trazendo assim, para a interpretação da narrativa, a interpretação discursiva. Logo voltaremos ao quinto movimento.

A ubicação das ações e a construção dos espaços é observada como estratégia narrativa, e a interpretação e compreensão dos conflitos e tensões da história está na base de todo o esforço interpretativo, pois processos de (re)construção identitárias, por serem relacionais e negociáveis, são necessariamente envolvidos por conflitos, tomados aqui como as relações identitárias estabelecidas que podem ser mais ou menos acirradas.

Grande parte do segundo e do terceiro movimento está embutida no primeiro movimento, sobretudo no procedimento de pré-construção narrativa laboviano, por meio do qual a narrativa é reconstruída de trás para frente (pré-construção narrativa), atribuindo-se relação de causalidade entre as sequências narradas. Estritamente ao segundo e terceiro movimentos restam: parte da interpretação metanarrativa alcançada com a atenção voltada para as estratégias de concatenação utilizadas e para suas possíveis explicações histórico-culturais; assim como a identificação dos elementos narrativos que compõem o conflito dramático a ser revelado no quarto movimento.

O quarto movimento é descrito por Motta como o movimento de "permitir ao conflito dramático se revelar”; na verdade não é dado aqui nenhum outro passo além dos já descritos nos movimentos anteriores. Esse quarto movimento aparece mais como um resultado das ações realizadas nos primeiros três movimentos do que como um movimento autônomo. Ao se identificarem os elementos que compõem o conflito dramático por meio da reelaboração e interpretação da narrativa a partir de suas sequências e episódios, já estamos permitindo ao conflito dramático se revelar, pois lembramos com Motta que "o conflito dramático é o frame cognitivo (enquadramento, perspectiva, ponto de vista) através do qual o narrador organiza a difusa e confusa 
realidade que pretende relatar" (MOTTA, 2013, p. 167). Nesse ponto da interpretação, o "frame cognitivo" do narrador já deve ter sido revelado e, com ele, o conflito dramático que marca a narrativa.

O quinto movimento exige ação dedicada do intérprete. Trata-se, nos termos de Motta, da personagem, "metamorfose da pessoa em persona” (MOTTA, 2013, p. 172). Nos termos que proponho, trata-se da interpretação da representação de atores sociais. Nesse ponto, as categorias de van Leeuwen (2008) ajudam a complementar a interpretação feita com instrumentos metodológicos da ACN e a fazer o elo entre os dois métodos utilizados na interpretação.

Como disse anteriormente, em vez de seguir única e fielmente com as ferramentas da ACN inicialmente utilizadas, ao escolher trabalhar com atores em vez de personagens, integro transdisciplinarmente a ACD à interpretação proposta. Nesse espaço de fronteira entre a análise da narrativa e a análise discursiva, entre o "plano da história" e o "plano do texto", lanço mão ainda de algumas propostas da narratologia usadas na caracterização de personagens, sobretudo trabalho com a ideia de Reis e Lopes (2007) de caracterização de personagens a partir de pares de ações opostas, o que é fundamental para a identificação de protagonismos e antagonismos.

Reforço que não me pareceu muito produtivo distinguir em minha interpretação o sexto e sétimo movimentos propostos por Motta. Nem como estratégia didática, pareceume de alguma valia separar os movimentos "estratégias narrativas" e "permitir as metanarrativas aflorar" dos outros cinco movimentos. Talvez por incapacidade de abstração, realmente não consigo esquadrinhar a interpretação até esses dois níveis, pois eles me parecem o próprio movimento interpretativo como um todo e não uma parte dele. Da forma como eu utilizo os outros movimentos, a interpretação é ela própria o "afloramento da metanarrativa" que se deixa brotar também por meio de "estratégias narrativas" acionadas e visualizadas nos outros movimentos de interpretação descritos.

\section{Categorias da Análise Crítica de Discurso na interpretação de fontes orais}

Conforme Bruner, "it was perhaps a decade ago that psychologists became alive to the possibility of narrative as a form not only of representing but of constituting reality" (BRUNER, 1991, p. 5). Esta é uma ideia de representação bastante marcante, e é com essa ideia que trabalho e que me parece trabalhar van Leeuwen em sua representação de atores sociais. Com uma representação que, no que representa, reconstrói, dentro de um 
entendimento dialógico em que a adversativa "ou" é constantemente substituída pela aditiva "e". Assim, em vez de pensarmos se representação "representa ou constrói", insistindo no pensamento dicotômico, podemos aceitar que representação "representa e constrói", tomando os rumos de novas formas de produção de conhecimento nas quais se encaixa a ACD. Conforme Hall, em seu didático texto sobre o trabalho da representação:

\begin{abstract}
Representation is an essential part of the process by which meaning is produced and exchanged between members of a culture. It does involve the use of language, of signs and images which stand for or represent things. But this is far from simple or straightforward process, as you will soon discover (HALL, 2013, p. 1).
\end{abstract}

A complexidade do processo resulta não do entendimento de que representação constrói significados por meio da linguagem, mas da compreensão de como esses significados são construídos, de quais os elementos que operam nessa construção. Das três abordagens teóricas da representação discutidas por Hall - a reflexiva, na qual a representação reflete o real; a intencional, na qual a representação é um processo cognitivo interno a quem a constrói; e a construtivista, na qual as representações são construídas nas relações entre coisas, conceitos e signos, a abordagem da ACD de van Leeuwen é a mesma adotada pelos Estudos Culturais, qual seja a aproximação construtivista em sua vertente discursiva derivada de Michel Foucault.

Cabe ressaltar que nessa vertente discursiva da abordagem construtivista não há uma dualidade entre representação e realidade, muito menos uma negação desta em favor daquela. A vertente discursiva da $\mathrm{ACD}$ não se presta às críticas dirigidas ao chavão "tudo é discurso". Segundo Hall:

Constructivists do not deny the existence of the material world. However, it is not the material world which conveys meaning: it is the language system or whatever system we are using to represent our concepts. It is social actors who use the conceptual systems of their culture and the linguistic and other representational systems to construct meaning, to make the world meaningful and to communicate about that world meaningfully to others (HALL, 2013, p. 11).

A abordagem construtivista da representação em sua vertente discursiva, ao apoiar-se na ideia de discurso, distancia-se da vertente semiótica do construtivismo mais preocupada com as produções de significados por meio das relações entre signos e linguagem, e se aproxima da interpretação social e cultural ao preocupar-se antes em entender como as práticas discursivas constroem conhecimento e poder em meio às representações construídas. A ideia de discurso não se coloca a questão se as coisas existem ou não, mas sim com as coisas adquirem sentido e são transformadas em meio às relações sociais onde são construídas as representações. 
Uma das contribuições mais importantes de van Leeuwen para a ACD deriva de suas considerações sobre a representação de atores sociais, que incorporo a minha proposta de interpretação de narrativas orais. Van Leeuwen propõem que a pergunta sobre como atores sociais podem ser representados é essencialmente uma questão gramatical, mas apenas se entendermos gramática como um "potencial de sentidos" ("what can be said") e não como um conjunto de regras (what must be said). Por isso, continua van Leeuwen:

I will not start out from linguistic operations, such as nominalization and passive agent deletion, or from linguistic categories, such as the categories of transitivy, but instead will draw up a sociosemantic inventory of the ways in which social actors can be represented and establish the sociological and critical relevance of my categories before I turn to the question of how they are realized linguistically (VAN LEEUWEN, 2008, p. 23).

É, então, a escolha dos atores sociais, de como eles são simbólica e semanticamente representados, antes que uma mera análise da estrutura linguística dos textos tomados como corpus, que guia este momento de interpretação de narrativas orais, lançando mão para isso das categorias definidas por van Leeuwen (2008, p. 52) passíveis de serem aplicadas às narrativas interpretadas.

Para introduzir as categorias de van Leeuwen, reproduzo abaixo, com adaptações, quadro explicativo elaborado por Ramalho e Resende (2011, p. 150), no qual as autoras apresentam uma seleção das categorias propostas por van Leeuwen (2008) em seu trabalho sobre a representação de atores sociais.

\begin{tabular}{|c|c|c|c|c|}
\hline \multirow{2}{*}{ Exclusão } & \multicolumn{4}{|l|}{ Supressão } \\
\hline & \multicolumn{4}{|c|}{ Colocação em segundo plano } \\
\hline \multirow{12}{*}{ Inclusão } & Ativação & \multicolumn{3}{|c|}{ Participação: papéis gramaticais participantes } \\
\hline & \multirow{2}{*}{ Passivação } & \multicolumn{3}{|c|}{ Participação como submetido a uma ação } \\
\hline & & \multicolumn{3}{|c|}{ Participação como benificiário de uma ação } \\
\hline & \multirow{7}{*}{ Personalização } & \multirow{3}{*}{ Determinação } & \multirow{2}{*}{ Categorização } & Funcionalização \\
\hline & & & & Identificação \\
\hline & & & \multicolumn{2}{|l|}{ Nomeação } \\
\hline & & \multicolumn{3}{|l|}{ Indeterminação } \\
\hline & & \multicolumn{3}{|l|}{ Generalização } \\
\hline & & \multirow{2}{*}{ Especificação } & \multicolumn{2}{|c|}{ Individualização } \\
\hline & & & \multicolumn{2}{|l|}{ Assimilação } \\
\hline & \multirow[b]{2}{*}{ Impersonalização } & \multicolumn{3}{|l|}{ Abstração } \\
\hline & & \multicolumn{3}{|c|}{$\begin{array}{l}\text { Objetivação: instrumentalização, autonomização de enunciados, } \\
\text { somatização, espacialização. }\end{array}$} \\
\hline
\end{tabular}

Quadro 1: Algumas possibilidades de representação de atores sociais

Fonte: Ramalho e Resende, 2011. 
O quadro é uma redução do quadro já simplificado de Ramalho e Resende, mas ainda nos permite uma visualização geral da proposta de van Leeuwen. Nos limites deste artigo, permito-me mais uma redução para apresentar apenas algumas categorias centrais, acreditando que a partir da explicação de algumas poucas categorias as demais possam ser compreendidas.

Em primeiro lugar, atores sociais, na proposta de van Leeuwen, podem ser representados por inclusão ou por exclusão. Neste último caso, pode ocorrer a supressão, quando os agentes de determinada ação narrada no texto não podem ser encontrados no próprio texto, ou a colocação em segundo plano, quando os agentes não são vinculados à ação narrada, mas podem ser encontrados no próprio texto, por vezes dedutivamente, com maior ou menor grau de certeza sobre a autoria da ação.

As formas de representar atores sociais por inclusão são bastante mais variadas e serão apresentadas de forma sucinta. Atores podem ser incluídos por ativação, aqueles que são representados como realizando a ação, ou por passivação, aqueles que são representados como submetidos à ação ou como beneficiários de seus efeitos, que podem ser tanto positivos como negativos. Em um detalhamento maior, atores podem ser passivamente representados como submetidos a uma ação na qual são representados como meta em um processo material; como fenômeno em um processo mental; ou como portador em um processo atributivo. Todas essas passivações são representadas por participação do ator representado como submetido à ação narrada. É possível também a passivação pela participação do ator representado como beneficiário de uma ação de efeito tanto negativo quanto positivo, o que pode ser feito colocando-se o ator como cliente em um processo material ou como dizente em um processo verbal.

As formas de passivação da representação de atores sociais pelo papel que desempenham em processos se tornam mais claras frente às estratégias de ativação de atores sociais que lhes são correlatas. Em relação aos processos, a ativação se realiza pela representação dos atores sociais sempre por papéis gramaticais participantes em estruturas transitivas em qualquer ação.

A distinção proposta entre personalização e impersonalização na representação de atores sociais incluídos no texto tem também relevância no método aqui proposta. A personalização ocorre pela representação de atores sociais com traços semânticos humanos, enquanto que a impersonalização implica ausência de traços semântico humanos na representação dos atores da ação. Esta última pode ser feita pela abstração, na qual atores são representados por qualidade atribuída pela e na própria representação, 
ou pela objetivação, na qual atores são representados por um local (espacialização), atividade (instrumentalização), parte do corpo (somatização) ou enunciados (autonomização de enunciados) a eles relacionados.

As estratégias de personalização são bem mais variadas dos que as de impersonalização. Atores podem ser representados de forma específica (especificação) tanto como indivíduos identificáveis (individualização), quanto como coletivos assimilados (assimilação) -, ou de forma generalizada (generalização). Podem ainda ser apresentados de forma indeterminada (indeterminação), geralmente com o uso de pronomes adjetivos indeterminados, ou de forma determinada (determinação), sendo aqui vários os desdobramentos. Para explicar algumas das várias das formas de determinação usadas na representação de atores sociais, recorro a citações de uma das autoras que elaboram o quadro analítico que serve de base para o Quadro 1. Segundo Resende:

\begin{abstract}
Atores sociais representados especificamente podem ser representados por seus nomes próprios (nomeação) ou pela função que desempenham na prática ou no evento social (categorização). Funcionalização e identificação são dois tipos fundamentais de categorização. Na funcionalização, os atores sociais são representados em termos de uma atividade, uma ocupação ou uma função. $\mathrm{Na}$ identificação, os atores são definidos não em termos do que fazem, mas em termos do que são (RESENDE, 2012, p. 446).
\end{abstract}

Todas as categorias aqui explicitadas de forma um tanto quanto fatigante se tornam mais dinâmicas e instigantes no momento da interpretação e ajudam a revelar estratégias narrativas e processos de identificação presentes nas entrevistas. Além disso, o trabalho com as categorias de van Leeuwen para a interpretação de atores sociais serve, na estrutura das interpretações, como elo entre a interpretação narrativa e a interpretação discursiva, acionada com o uso que faço de van Leeuwen e continuada com o uso que faço de categorias da ACD definidas por Fairclough (2003).

Fairclough (2003) apresenta um rol de ferramentas metodológicas, as quais agrupa em três categorias teóricas, ou melhor, em três grandes significados que compõem o elemento discursivo das práticas sociais: o significado acional, o significado representacional e o significado identificacional. O significado acional é representado nos gêneros discursivos, vistos como diferentes formas de agir e interagir textualmente. O significado representacional se identifica com os discursos em seu sentido mais concreto: os modos como atores, eventos e práticas são representados em textos. Por fim, o significado identificacional age na construção de identidades nos textos, na manifestação discursiva das formas de ser, e está, portanto, mais relacionado ao estilo.

Segundo Resende e Ramalho: 
Fairclough (2003) postula uma correspondência entre ação e gênero, representação e discurso, identificação e estilo - gêneros, discursos e estilos são modos relativamente estáveis de agir, de representar e de identificar, respectivamente. A análise discursiva é um nível intermediário entre o texto e seu contexto social - eventos, práticas, estruturas. Então, a análise de discurso deve ser simultaneamente a análise de como os três tipos de significado são realizados em traços linguísticos dos textos e da conexão entre o evento social e práticas sociais, verificando-se quais gêneros, discursos e estilos são utilizados e como são articulados no texto (RESENDE; RAMALHO, 2009, p. 61).

Creio que, ao ressaltar o paralelismo dos termos de Fairclough importados da Linguística Sistêmico Funcional com as ideias de evento, prática e estrutura, bastante comuns na interpretação histórica e social, Resende e Ramalho tornam clara aos/às leitores/as pouco acostumado/as com o jargão da análise linguística as possibilidades do uso da ACD na interpretação social e também na interpretação cultural. Arrisco-me a ampliar o paralelismo traçado pelas autoras entre a análise linguística e a análise social, defendendo seu uso para uma interpretação histórico-cultural, numa analogia tanto entre o lugar que ocupa a ACD entre texto e contexto, quanto entre o lugar que ocupa a interpretação histórico-cultural entre práticas e representações.

Ainda sobre os três significados propostos pela vertente de ACD aqui abordada, cabe lembrar com Fairclough (2003) que a divisão do elemento discursivo das práticas sociais em três significados é um recurso metodológico que não pode elidir o fato de que esses três significados coexistem e são um do outro indissociáveis. Os três significados englobam as categorias de interpretação que são de fato utilizadas para o trabalho com o texto e a aproximação ao discurso. Antes, contudo, de abordar as categorias utilizadas nesta proposta metodológica interdisciplinar, cabem algumas reflexões sobre o que é aqui chamado de texto e o que é chamado de discurso, visto serem estes conceitos polissêmicos, não significando o mesmo, por exemplo, na ACN e na ADC, ou em outras diferentes propostas de interpretação textual.

Devido à polissemia dos termos, devo então esclarecer que trabalho com as definições de discurso e texto da ACD, reconhecendo uma diferença nítida entre esses dois conceitos. Diferença que se esfumaça mesmo em outras práticas de análises textuais - podendo ser mesmo desprezada em algumas propostas, como o faz Eugenio Coseriu em sua Lingüística Textual (COSERIU, 2007) -, mas que é muito fecunda em ACD, pois ajuda a definir algumas categorias de interpretação importantes, como, por exemplo, interdiscursividade e intertextualidade.

Em ACD a ideia de discurso é apropriada do pensamento de Michael Foucault em duas de suas dimensões: em um sentido mais abstrato, como o conjunto das enunciações 
já realizadas ou potenciais que envolvem questões de poder; ou em um sentido dotado de uma maior concretude, que permite falarmos em discursos sobre relações particulares de poder, como, por exemplo, o discurso científico, o discurso religioso, o discurso econômico etc. Apoiada na apropriação das ideias de discurso de Foucault, uma das definições mais precisas e sucintas de discurso para a ACD talvez seja a de Norman Fairclough (2003), que define discurso como um dos elementos componentes da prática social, que implica em um modo de agir sobre o mundo e sobre os outros e/ou um modo de representação do mundo. Diferentes discursos seriam, pois, diferentes formas de representar e de agir sobre o mundo. Discursos são maneiras específicas de representar aspectos do mundo, posicionadas histórica, social e culturalmente.

Assim como ocorre com a ideia de discurso, há uma infinidade de definições de texto, que se enquadram ou não em determinada prática de interpretação textual. Por levar em consideração não só aspectos linguísticos, mas também aspectos cognitivos e, principalmente, aspectos sociais e culturais, uma definição linguisticamente orientada bastante abrangente e parcialmente adequada à ACD é de Koch e Vilela, que propõem ser o texto:

\begin{abstract}
Uma manifestação verbal constituída de elementos lingüísticos intencionalmente selecionados e ordenados em seqüência durante a atividade verbal, de modo a permitir aos parceiros, na interação, não apenas a depreensão de conteúdos semânticos, em decorrência de processos e estratégias de ordem cognitiva, como também a interação ou atuação de acordo com práticas sócioculturais (Koch; Vilela, 2001, p. 454).
\end{abstract}

Para adequarmos a definição de Koch e Vilela à ACD, devemos lembrar que, para a $\mathrm{ACD}$, textos não se restringem a manifestações verbais, nem a elementos linguísticos; os exemplos mais claros dessa maior abrangência do texto em ACD são as análises de textos imagéticos ou de textos multimodais. Textos são encontrados em quaisquer instâncias de linguagem em uso, ultrapassando o verbal, oral ou escrito, e incluindo outros sistemas semióticos, como textos visuais ou multimodais.

Unidade mínima de análise em ADC por serem considerados a concretização de discursos específicos, e serem a parte observável dos potenciais discursivos, textos resultam de eventos concretos realizados e empíricos, cuja observação pode levar o intérprete a inferir aspectos de potenciais discursivos de determinada estrutura social, pois resultam da estruturação social da linguagem, sendo ao mesmo tempo possíveis transformadores dessa estruturação, acarretando mudança social. Para a ACD é importante ressaltar que textos são produtos sociais historicamente localizados, são 
elementos estruturados e estruturantes das relações sociais, por terem efeitos causais, isto é, serem passíveis de provocar a mudança social ou de reforçar as estruturas vigentes.

Sobretudo cabe destacar a diferença entre texto e discurso, seja este último em sua definição mais abstrata ou mais concreta. Textos não se confundem com discursos, pois são manifestações de discursos, qualquer discurso é sempre maior que qualquer uma de suas manifestações e não se restringe à soma de todas elas, pois sempre existirão aspectos do discurso ainda não manifestados em textos. Além disso, textos são geralmente compostos de mais de um discurso, o que muitas vezes impede que um texto seja enquadrado em determinado discurso. A rigor, os objetos de interpretação da ACD são textos e não discursos, é o texto que permite ao intérprete chegar a alguns aspectos de alguns discursos. Para Resende e Ramalho, "textos representam materializações discursivas eventuais que devem ser analisadas" (RESENDE; RAMALHO, 2009, p. 92). Discursos se concretizam por meio de textos, mas são mais abrangentes que eles. Duas das categorias de interpretação da ACD faircloughiana decorrem imediatamente da distinção esboçada entre texto e discurso, quais sejam, intertextualidade e interdiscursividade, abordadas a seguir de forma relacional.

A intertextualidade poderia ser brevemente definida com a maneira pela qual textos se baseiam, incorporam, recontextualizam e dialogam com outros textos, trazem outras vozes além da voz do autor ao texto. É muitas vezes marcada pela presença de elementos textuais externos ao texto interpretado na forma de citações. Essas citações podem ocorrer de maneiras diversas: relato direto, relato indireto, relato indireto livre, relato narrativo de ato de fala ou pressuposições, essas últimas consideradas formas de relacionar textos a uma série indefinida de outros textos que tenham sido ditos, escritos ou mesmo pensados anteriormente, considerados pelo/a narrador/a de conhecimento compartilhado entre ele e seus/suas narratários/as.

A análise textual com relação ao critério intertextualidade pode ajudar a desvelar o interdiscurso em que se situa determinado texto, que discursos estão possivelmente inculcados nas representações dos autores dos textos interpretado. Se, como veremos, nem toda intertextualidade é interdiscursividade, a recíproca não é verdadeira. Por serem materializados em textos, discursos que se encontram e dialogam em um único texto, denotam sempre além da interdiscursividade um caso de intertextualidade, ainda que somente por pressuposição.

A concepção de intertextualidade deriva das ideias seminais de Bakhtin (1994) de dialogicidade e polifonia dos textos: todo e qualquer texto, mesmo que aparentemente 
monológico, é dialógico, pois responde a outros textos já formulados ou não. Há, sobretudo na Linguística Textual, uma preocupação em diferenciar polifonia de intertextualidade, propondo que aquela seja mais abrangente que esta, que seria, por sua vez, a manifestação mais frequente da polifonia. Devido à compreensão mais larga de texto em ACD, é ainda mais trabalhoso, e talvez menos frutífero, tentar estabelecer fronteiras entre as duas categorias, sendo mais comum ao intérprete crítico de discurso trabalhar com uma noção ampliada de intertextualidade, derivada da ideia bakhtiniana de polifonia dos textos. Dentro dessa noção ampliada é mister destacar, como o fazem Resende e Ramalho (2009, p.100-101), que “intertextualidade é uma questão de recontextualização, ou seja, um movimento de um contexto a outro que acarreta transformações particulares dependendo de como o material é movimentado". Na preocupação de crítica social primordial à $\mathrm{ACD}$, arrisco-me a dizer que pode ser mais relevante perceber e interpretar os movimentos de recontextualização de vozes ou textos que propriamente tentar classificá-los como tais.

Como foi dito na distinção entre texto e discurso, em um mesmo texto podemos encontrar discursos distintos. Reconhecer diferentes discursos dentro de um texto é bastante importante para a interpretação crítica de discursos, pois é a partir daí que processos históricos, como lutas hegemônicas discursivamente e historicamente constituídas, ou como reconstruções identitárias de sujeitos históricos, podem se tornar inteligíveis por meio do texto. É, contudo, crucial perceber que assim como o discurso é mais abrangente que o texto, interdiscursividade não se restringe à intertextualidade, pois o interdiscurso não é composto apenas pelo encontro de textos, por discursos materializados, mas também pelos discursos ainda não materializados, pelo não-dito ou dito e já olvidado.

Voltando um pouco ao início desse tópico para podermos avançar sem perder o fio da meada, lembramos que interdiscursividade está relacionada ao significado representacional, ao discurso; enquanto que intertextualidade está relacionada ao significado acional, ao gênero, às maneiras de agir. Sustentando a interpretação no tripé de significados proposto por Fairclough (2003), além da interdiscursividade, da intertextualidade e de suas manifestações textuais por meio das diversas formas de citação elencadas, incluo na proposta metodológica categorias do significado identificacional, ligado ao estilo.

O estilo é um aspecto discursivo das formas de ser, relacionado à 'identidade' ou, mais especificamente, à 'identificação', à forma como as pessoas se identificam ou são 
identificadas por outrem (RESENDE; RAMALHO, 2009). Na ADC o estilo serve para detectar as identificações mais proeminentes no texto, traçando os seus processos textuais de identificação. Além disso, pode ser observado como as identificações traçadas se relacionam entre si, com que grau de reciprocidade e simetria, como a diferença entre elas é tratada e que lugar ou espaço é conferido à dialogicidade. Duas categorias textuais intimamente relacionadas ao estilo são a modalidade e a avaliação, sendo a primeira relacionada ao comprometimento com o dito, com sua verdade ou urgência, e a segunda relacionada a seu posicionamento com relação ao dito ser algo desejável ou não, bom ou ruim.

A categoria modalidade em ACD permite interpretar a relação estabelecida entre o autor e as representações de mundo expressas no texto. O uso de modalizadores é importante, sobretudo, na interpretação do significado identificacional, ou seja, na construção discursiva de identidades e identificações presentes no texto (FAIRCLOUGH, 2003). É por meio de modalizadores que o autor se compromete ou se afasta mais ou menos das representações enunciadas e não apenas das representações de identidade, embora estas sejam especialmente relevantes nesse aspecto. Apoiando-se na Linguística Sistêmico-Funcional de Michael Halliday, Fairclough (2003) propõe que a modalidade varia gradativamente entre um polo positivo a um polo negativo, incluindo-se aí os polos, ao contrário de Halliday, que os exclui. Fairclough (2003) chama de modalidade categórica a que é expressa como um dos polos positivo ou negativo, que para Halliday seriam não modalizados. Na proposta de Fairclough (2003), além da modalização categórica, que pode ser afirmativa ou negativa, encontramos as seguintes modalidades: modalização epistêmica, que denota o comprometimento do/a autor/a com o grau de verdade do enunciado; e modalização deôntica, que marca o compromentiomento com o grau de obrigatoriedade expresso em um enunciado. Além disso, segundo o nível de comprometimento, as modalizações epistêmicas e deônticas podem ainda ser subcategorizadas em modalização epistêmica/deôntica com alto nível de comprometimento; modalização epistêmicaldeôntica com nível médio de comprometimento e modalização epistêmica/deôntica com baixo nível de comprometimento (FAIRCLOUGH, 2003).

Os marcadores de modalidade são variados e podem ser léxico-gramaticais ou não. Entre aqueles, os mais comuns são os verbos, advérbios e adjetivos modais (como, por exemplo, querer, poder, certamente, provavelmente, provável, possível etc.), além de verbos que indicam processos mentais (como, por exemplo, “eu penso', “eu acho”, “eu 
creio" etc.). Entre os outros, a prósodia é um dos mais interessantes para o caso das narrativas orais, as hesitações expressas na pausa e na diminuição da entonação ou as concordâncias e ênfases feitas com o aumento da entonação podem, por exemplo, ser interpretadas como marcadores de modalidade.

A avaliação é outra categoria que assume grande relevância na interpretação do significado identificacional do texto, ou seja, em outros termos, nos processos de (re)construção discursiva de identidades e identificações presentes nas narrativas interpretadas. Ainda na esteira de Fairclough, as avaliações não se limitam às claras afirmações avaliativas encontradas no texto, "but also other more or less explicit or implicit ways in wich authors commit themselves to values" (FAIRCLOUGH, 2003, p. 171). Esses caminhos mais ou menos explícitos com os quais autores/as se comprometem com valores se cruzam muitas vezes com o uso de modalizadores, o que leva Fairclough a subcategorizar as avaliações em: afirmações avaliativas; afirmações com modalidades deônticas; afirmações com processos mentais afetivos, e valores presumidos. Na definição de Fairclough, afirmações avaliativas trazem enunciados sobre o que é desejável ou não desejável, sobre o que é bom é o que é ruim. Muitas vezes, são realizadas em processos relacionais por meio do uso de adjetivos, mas podem também ser marcadas por outros processos em que verbos, advérbios, ou mesmo exclamações podem ser os marcadores da avaliação (FAIRCLOUGH, 2003).

Afirmações com modalidades deônticas seguem, obviamente, o uso de modalizadores que denotam também avaliação. As afirmações com processos mentais afetivos podem surgir com modalizadores marcados por verbos que indicam processos mentais, mas também podem surgir diretamente por meio de atributos que indicam afetividade (por exemplo, "isso me emociona"). Por fim, Fairclough destina a subcategoria de avaliação com valores presumidos para a identificação de casos de avaliação que ocorrem sem marcadores seja de afirmação avaliativa, seja de modalização deôntica, ou de processo mental afetivo. Seguindo Fairclough, os valores presumidos estão frequentemente muito mais profundamente embutidos no texto, que dependem de "an assumption of shared familiarity with (not necessarily acceptance of) implicit value systems between author and interpreter" (FAIRCLOUGH, 2003, p. 173).

Selecionei aqui algumas ferramentas de trabalho com a linguagem que me foram uteis até agora em interpetação já realizadas, elas não são as únicas, nem definitivas, mas são suficientes para cobrir a lacuna denunciada por Verena Alberti (2003) e Lynn Abrams (2010) que me serviram para o início das reflexões deste artigo. As ferrametnas da ACD 
apresentadas complementamo trabalho de interpretação, cujos passos principais são dados por meio da interpretação cultural de narrativas proposta pela análise crítica de narrativa e descrita no subtítulo anterior. É na interpretação cultural das narrativas orias que se centra a proposta.

\section{Considerações finais}

Para concluir, devo explicitar que nos limites do artigo aqui proposto não caberia a apresentação de uma interpretação de narrativa oral usando o método interdisciplinar aqui proposto, uma vez que a descrição do método e não sua exemplificação foi o objetivo do artigo. Posso, contudo, remeter o leitor a outras interpretações, nas quais o método é utilizado. A proposta central aqui foi a apresentação esmiuçada de um caminho de interpretação narrativa da cultura que vá além da repetida e importante afirmação do caráter narrativo da organização das experiências humanas. Em meu trabalho de interpretação de processos de invenção e negociação de identidades por meio de narrativas de trajetórias de vida de imigrantes brasileiros e brasileiras na Europa (FEIJÓ, 2015), é possível acompanhar a utilização do método aqui exposto. Lá são feitas três interpretações completas com narrativas orais de trajetórias de vida, cujas transcrições ultrapassaram trinta páginas de texto, volume textual que tornaria hercúleo um meticuloso trabalho de interpretação cultural fundado nos mecanismos narrativos e discursivos da linguagem. Com o método aqui proposto, é feita uma sinopse narrativa de aproximadamente três páginas para cada transcrição, o que corresponde ao movimento de reestruturação da narrativa. As narrativas reestruturadas puderam então ser culturalmente interpretadas por meio das estratégias de linguagem desenvolvidas. O leitor ou leitora que sentir necessidade de maior amparo para a compreensão e, quiçá, utilização do método aqui proposto, pode então consultar os exemplos de aplicações disponíveis em Feijó (2015).

\section{Referências}

ABRAMS, L. Oral history theory. 1. ed. London: Routledge, 2010.

ALBERTI, V. Narrativas na História Oral. In: SIMPÓSIO NACIONAL DE HISTÓRIA, 22. 2003, João Pessoa. Anais... João Pessoa: ANPUH, 2003, 10f. CD-ROM. Disponível em: <http://cpdoc.fgv.br/producao_intelectual/arq/1346.pdf>. Acesso em: 10 fev. 2018. 
BAKHTIN, M. The dialogic imagination. 8. ed. Austin: University of Texas Press, 1994.

BAL, M. Close Reading today. From Narratology to cultural analysis. In: GRÜNZWEIG, W.; SOLBACH, A. Grenzüberschreitungen: Narratologie im Kontext. 1. ed. Tübingen: Gunter Narr, 1999. p. 19-40.

BAMBERG, M. (Ed.). Oral versions of personal experience. Three decades of narrative analysis. Journal of Narrative and Life History, Amsterdam, v. 7, n. 1-4, p. 1-415, 1997. (A special issue)

BRUNER, J. The narrative construction of reality. Critical Inquiry, Chicago, v. 18, n. 1, p. 121, 1991.

COSERIU, E. Textlinguistik: eine Einführung. 4. ed. Tübingen: Gunter Narr Verlag, 2007.

FAIRCLOUGH, N. Analysing Discourse. 1. ed. London: Routledge, 2003.

FEIJÓ, G. V. O Brasil lá fora: a invenção de nacionalidades brasileiras na Alemanha e em Portugal (1989-2012). Narrativas e Discursos de Identidade. 2015. 480f. Tese (Doutorado em História) - Instituto de Ciências Humanas, Universidade de Brasília, Brasília, 2015.

FEIJÓ, G. V. A análise crítica de narrativa na interpretação de narrativas orais. In: CONGRESSO IBERO-AMERICANO DE INVESTIGAÇÃO QUALITATIVA, 6, 2017, Salamanca. Anais... Oliveira de Azeméis: Ludomedia, 2017. p. 500-511.

HALL, S. The Work of Representation. In: HALL, S.; EVAN, J.; NIXON, S. (Eds.). Representation: Cultural Representations and Signifying Practices. 2. ed. London/ Milton Keynes: Sage/ Open University, 2013. p. 1-47.

KOCH, I; VILELA, M. Gramática da Língua Portuguesa. 1. ed. Coimbra: Almedina, 2001.

LABOV, W. Some Further Steps in Narrative Analysis. Journal of Narrative and Life History, Amsterdam, v. 7, n. 1-4, 1997, p. 395-415.

LABOV, W. Uncovering the event structure of narrative. In: TANNEN, D.; ALATIS, J. (Orgs.). Georgetown University Round Table 2001. 1. ed. Washington: Georgetown University Press, 2003. p. 63-83.

LABOV, W. Narrative Pre-Construction. Narrative Inquiry, Amsterdam, v.16, n. 1, p. 37-45, 2006.

LABOV, W. Narratives of personal experiences. In: HOLGAN, P. C. (Org.). Cambridge Encyclopedia of Language Sciences. 1. ed. Cambridge: Cambridge University Press, 2010a, p. 782.

LABOV, W. Where should I Begin? In: SCHIFFRIN, D.; DE FINA, A.; NYLUND, A. (Orgs.). Telling stories: language, narrative and social life. 1. ed. Washington: Georgetown University Press, 2010b. p. 7-22.

LABOV, W.; WALETZKY, T. Narrative Analysis. Oral Versions of personal experiences. In: PAULSTON, C. B.; TUCKER, G. R. Sociolinguistics. The essential readings. 1. ed. London: Blackwell, 2003. p. 74-104.

MOTTA, L. G. Análise crítica da narrativa. 1. ed. Brasília: Editora da UnB, 2013. 
NÜNNING, A.; NÜNNING, V. Neue Ansätze in der Erzähltheorie. 1. ed. Trier: Wiss. Verlag, 2002.

RAMALHO, V.; RESENDE, V. Análise de Discurso (para a) Crítica. 1. ed. Campinas: Pontes, 2011.

RESENDE, V.; RAMALHO, V. Análise de Discurso Crítica. 1. ed. São Paulo: Contexto, 2009.

REIS, C.; LOPES, A. C. M. Dicionário de narratologia. 7. ed. Coimbra: Almedina, 2007.

RESENDE, V. de M. Representação discursiva de pessoas em situação de rua no "Caderno Brasília": naturalização e expurgo do outro. Linguagem em (Dis)curso, Tubarão, v. 12, n. 2, p. 439-465, 2012.

VAN DIJK, T. A. Episodes as units of discourse analysis. In: TANNEN, D. (Org.). Analyzing Discourse: Text and Talk. 1. ed. Georgetown: Georgetown University Press, 1982. p. 177-105.

VAN LEEUWEN, T. Discourse and Practice. New tools for Critical Discourse Analysis. 1. ed. New York: Oxford University Press, 2008.

Recebido em: 24 de março de 2018.

Aceito em: 04 de abril de 2018. 